\title{
Consagração universitária, capitais simbólicos e cargos financeiros: o estudo do perfil dos engenheiros de produção na Universidade Politécnica de São Paulo
}

\author{
Thais Joi Martins' \\ Julio Cesar Donadone ${ }^{2}$
}

\section{Resumo}

O objetivo central deste artigo é o de dar destaque à análise dos capitais simbólicos (em específico o cultural), gostos e estilos de vida dos engenheiros de produção (egressos) da Universidade Politécnica de São Paulo (USP). Apreciaremos neste artigo, por meio da metodologia qualitativa e consequente uso de entrevistas semiestruturadas, a proposição de que os marcadores simbólicos encaminham esses engenheiros (gestores) para cargos no mundo das finanças, tais quais, as consultorias financeiras e o mercado financeiro. Podemos constatar que existem homologias no que diz respeito aos marcadores simbólicos citados e a ocupação desses profissionais nesses últimos cargos de destaque. Para além da constatação anterior, cabe mencionar que esses arautos das finanças são justamente os novos agentes que estão intermediando e alimentando dinâmicas e jogos de poder dentro do atual capitalismo financeiro.

Palavras-chave: Capital simbólico. Gosto. Estilos de vida. Sociologia de Pierre Bourdieu. Sociologia econômica e das finanças.

Doutora em Ciência Política pela UFSCar. Professora na Universidade Federal do Recôncavo da Bahia (UFRB). E-mail: thaisjoi@gmail.com

2 Doutor em Engenharia de Produção pela USP. Professor na Universidade Federal de São Carlos (UFSCar). E-mail:donadojc@uol.com.br Commons. Com essa licença você pode compartilhar, adaptar, para qualquer fim, desde que atribua a autoria da obra, forneça um link para a licença, $e$ indicar se foram feitas alterações. 


\section{Introdução}

Esse artigo tem como objetivo mais amplo verificar se os marcadores de uma dada cultura legítima (capitais simbólicos ${ }^{3}$ ) estudados por Bourdieu (2008) criam sistemas homólogos no Brasil. Ou seja, nos inquerimos a respeito da existência de possíveis homologias entre os capitais simbólicos adquiridos pelo grupo social estudado e o capital de chegada (circunstância em que os indivíduos ocupam cargos no mercado de trabalho depois de formados). Nesse sentido, examinamos a proposição de que os capitais simbólicos (principalmente o cultural) bem como os sistemas coadjuvantes a eles, a saber, a origem social, os gostos e estilos de vida, poderiam influenciar de alguma forma a escolha da ocupação dos engenheiros de produção da Universidade Politécnica de São Paulo (USP), quando eles optam por posiçóes relativas aos altos cargos de finanças no País (gestóes empresariais e organizacionais).

Apesar da diferenciaçáo de ocupaçóes que um engenheiro de produção possa escolher, as posiçóes mais apontadas por eles se dicotomizam entre a área industrial e a área financeira, como é o caso respectivamente das ocupaçóes relativas ao setor do chão de fábrica e, das consultorias e do mercado financeiro. Nesse sentido, averiguamos na primeira parte de nossa análise de dados como se perfilam os gostos e os capitais simbólicos dos estudantes e egressos de engenharia de produção de uma universidade consagrada no Brasil e se essas características socializadoras se agrupam homologamente a ocupação de alguns setores profissionais.

Por fim, detectamos que nem todos os alunos da Universidade Politécnica de São Paulo detém uma aproximação com a cultura dita "legítima”, estes últimos, seriam justamente os estudantes/egressos cujas afinidades eletivas, capitais simbólicos e, consequentemente os mecanismos de reprodução social atrelados a estes, atuam diretamente no processo de distanciamento da ocupação de cargos financeiros bem remunerados. Para

3 Cabe destacar que a noção de capital simbólico usada nesse artigo vai de encontro com a construção argumentativa de Pierre Bourdieu em seu livro Escritos de Educação. Ou seja, o autor menciona o capital simbólico como uma adequação entre o capital cultural, social e econômico. Vale ressaltar que em outras obras como A distinção (2008) o autor trabalha com o conceito de capital simbólico dentro das nuances de prestígio e das honrarias. 
entendermos melhor como os mecanismos de reprodução se ajustam ao afastamento ou aproximação da ocupação dos cargos financeiros altamente almejados, ou seja, para compreendermos como funcionam os sistemas de homologias no presente caso, apresentamos alguns fragmentos de entrevistas com egressos politécnicos que se graduaram na universidade em décadas distintas ${ }^{4}$.

Nessas entrevistas, localizamos a possível existência de homologias entre seus marcadores simbólicos de cultura legítima/não legítima e a aproximação/distanciamento desses com um cargo profissional de prestígio no universo das finanças. ${ }^{5}$ Antes, porém, de averiguarmos os dados da pesquisa de campo, faremos uma breve síntese dos principais conceitos apresentados nessa pesquisa, especialmente os de capital cultural, gosto e estilos de vida, a fim de mostrar como a sociologia do gosto pode se articular conceitualmente com a presente pesquisa. Junto a essa sucinta retomada de alguns conceitos, convidamos os leitores interessados no tema a revisitarem a sociologia de Pierre Bourdieu cuja extensão e complexidade dos conceitos não poderão ser abarcadas em um artigo que tem como prioridade a explanação e análise dos dados coletados. ${ }^{6}$

\section{A Sociologia do Gosto}

Pierre Bourdieu (2007) assinala que o capital cultural pode estar disposto em três formas distintas: o capital no estado incorporado (disposiçóes duráveis), no estado objetivado (bens culturais) e no estado institucionalizado (certificação escolar). O primeiro deles está relacionado ao corpo, ou seja, ele é adquirido quando incorporado sendo que, esse processo de incorporação leva um determinado tempo, ou seja, depende do capital que a família possui e que será transmitido para um indivíduo se houver tempo

4 Para o atual artigo trouxemos somente as falas dos egressos do curso devido ao curto espaço que deve-se discorrer em um artigo. No entanto, também entrevistamos alunos que cursavam o curso e se situavam nos últimos anos da graduação.

5 É importante destacar que essa pesquisa contou com análise de dados estatísticos e análise de correspondência múltipla, no entanto, nosso objetivo central é mostrar nesse artigo o valor e o significado da análise qualitativa, uma vez que confirma veementemente as análises quantitativas.

6 Nesse sentido, dentre os muitos estudos sobre o autor, recomendamos os trabalhos de Gabriel Peters, a saber, "Habitus, reflexividade e neo-objetivismo na teoria da prática de Pierre Bourdieu" (2013), entre outros. 
disponível para tal ensino-aprendizado. Esse tipo de capital será expresso posteriormente na forma de habitus de um indivíduo ou grupo social.

Já o capital objetivado pode ser transferido materialmente e por essa razão, se diferencia do capital incorporado. Sabe-se que para se adquirir um objeto basta possuir capital econômico, no entanto, para sabermos qual a utilidade dada a esse objeto adquirido, é necessário antes ter apreendido o capital cultural incorporado. Esse capital cultural objetivado pode ser usado como instrumento de luta em um dado campo, como por exemplo, por meio da manifestação de sua distinção social. $\mathrm{O}$ último tipo de capital cultural é o institucionalizado e pode ser materializado por meio do diploma e, esse por sua vez, contido de institucionalidade pelo processo de magia social e da crença coletiva, atribuirá reconhecimento aos indivíduos que o possuírem. Nesse sentido, é dentro da argumentaçáo anterior que Bourdieu (2007, p. 113) ainda assinala que:

Eis ai um dos mecanismos que, acrescentando-se a lógica da transmissão do capital cultural, fazem com que as mais altas instituições escolares, e em particular aquelas que conduzem a posição de poder econômico, e político, continuem sendo exclusivas como foram no passado. E fazem com que o sistema de ensino, amplamente aberto a todos e, no entanto, estritamente reservado a alguns, consiga a façanha de reunir as aparências da democratização com a realidade da reprodução que se realiza em um grau superior de dissimulação, portanto, com um efeito acentuado de legitimação social.

Outro conceito que será citado na análise das entrevistas é o conceito de gosto, que por sua vez, pode ser referir a um marcador de classe, além de ser legitimador dos mecanismos de distinção. Portanto,

O gosto classifica aquele que procede a classificação: os sujeitos sociais distinguem-se pelas distinções que eles operam entre a belo e a feio, a distinto e o vulgar; por seu intermédio, exprime-se ou traduz-se a posição desses sujeitos nas classificações objetivas. (BOURDIEU, 2008, p. 12).

O gosto, além de ser uma preferência, é antes um repúdio, o asco, a não identificação com açóes, gestos, características dos outros. Essa aversão pelos estilos de vida dos outros é o que podemos dizer que define o limite entre as classes e fraçóes de classes sociais. Parafraseando Pierre Bourdieu, podemos expor a seguinte linha de raciocínio: o gosto, que opera por meio 
dos mecanismos de distinção social que, por sua vez, se objetiva nas práticas sociais, (que possuem um poder de classificar e desclassificar) acaba por ser a expressão de uma classe ou fração de classe social. Já a classe, nada mais é do que a representação de uma posição no espaço social, e essa, por sua vez, é reproduzida dentro das famílias e grupos sociais. Essa reprodução pode se fazer de modo que muitas "necessidades" sejam travestidas em formato de "estratégias" ou mesmo que muitas "obrigações" sejam mascaradas e se apresentem como "preferências".

Essas preferências ou escolhas, por sua vez, (sendo ou não obrigaçóes, dependendo da posição social ocupada pelos indivíduos) definem de certa forma os destinos sociais dos grupos ou dos indivíduos. Já os estilos de vida estão circunscritos aos gostos, sendo que se conformam como a manifestação prática dos gostos e das disposições incorporadas em forma de habitus no cotidiano. Logo, de acordo com Bourdieu, os estilos de vida são "[...] diferentes sistemas de propriedades em que se exprimem os diferentes sistemas de disposiçôes." (BOURDIEU, 2008, p. 236). Explicitados brevemente os conceitos podemos dar início a exposição e análise das entrevistas. ${ }^{7}$

\section{Do gosto aos capitais simbólicos: as falas dos egressos do Curso de Engenharia de Produção da Universidade Politécnica de São Paulo}

Com a leitura do livro "A escola politécnica - 100 anos", criado pela associação de ex-alunos da Poli no ano de 1993, pudemos obter algumas

\footnotetext{
Optamos por discorrer brevemente sobre os conceitos a fim de que pudéssemos dar mais atenção às entrevistas e as falas do maior número possivel de inqueridos dentro do espaço para um artigo. Conseguimos sistematizar sete entrevistas ou elementos mais importantes dessas entrevistas, que por sua vez foram explanadas de formas diversas para não cansar o leitor (ora no formato de quadro, ora de forma descritiva, ora usando a voz do pesquisador e ora usando a voz dos entrevistados). Outro fato importante é o de que essas entrevistas expressam o conteúdo geral de dados estatísticos que formam sistematizados quando analisamos prosopograficamente os questionários de 80 alunos que ainda estudavam na Universidade Politécnica de São Paulo. Ao mesmo tempo, entrevistamos 15 egressos que puderam nos explanar como se conformava $o$ universo de suas respectivas salas de aulas e descrever as principais características dos estudantes que fizeram o curso junto a eles por pelo menos quatro anos. Escolhemos um montante de alunos que expressava a sua respectiva década de estada na universidade, por isso, temos representantes das décadas de 1970, 1980, 1990 e anos 2000
} 
informações históricas sobre a escola. A Universidade Politécnica de São Paulo (Poli) foi criada no ano de 1893, momento em que a cidade de São Paulo ainda não estava em seu pleno desenvolvimento e sua população era de aproximadamente 240 mil habitantes. A ideia da criação de uma escola de engenheiros no Brasil advém da elite vanguardista de liberais, que luta por uma lógica republicana que insira a modernidade e o progresso no País. E nesse sentido que

A elite paulistana, afinada com os ideais da segunda revolução industrial, lançava assim o brado em favor da industrialização, guiada pelos engenheiros preparados por escolas apareIhadas nos moldes dos grandes centros europeus. (HUBER; SOUZA, 1993, p. 10).

Desde sua criação e principalmente a partir dos anos 1960 até os dias de hoje, a Escola Politécnica é conhecida, no Brasil, pelo poderio de seus grandes engenheiros que conseguiram desenvolver o País economicamente e tecnologicamente. Náo nos faltam exemplos como o pioneirismo em fermentação alcoólica com melaço de cana-de-açúcar pela engenharia química, a criação do Projeto Radam na área de sensoriamento remoto, a engenharia hidráulica responsável pelo serviço de telemetria para prever cheias e enchentes, a construção das ferrovias de transportes para trens urbanos, a fabricação do concreto, as redes de fibra ótica, a engenharia da computação com dispositivos digitais, a engenharia de energia com a construção do carro elétrico, a engenharia naval com as pesquisas com fibras de carbono etc.

Portanto, podemos constatar que a justificativa de escolhermos estudar o Curso de Engenharia de Produção da Escola Politécnica de São Paulo pode ser encontrada na trilogia de Alexandre D'Alessandro, na qual ele nos remete às memórias cotidianas sobre os alunos da Universidade Politécnica desde a sua fundação. Essas memórias são importantes, pois conseguimos resgatar algo sobre o cotidiano e o estilo de vida dos alunos da escola. Podemos perceber que os alunos dos anos iniciais possuíam um alto capital social, cultural e econômico. Com a presente pesquisa, busca-se constatar uma possível propagação da reprodução social dos capitais (social, cultural e econômico) hodiernamente e, como esses capitais poderiam direcionar esses engenheiros para a ocupação de cargos de destaque. Por isso a escolha de uma das universidades mais consagradas e elitizadas do País que começa formando engenheiros industriais e que hoje forma grande parte da elite financista do Brasil. 


\section{Metodologia, caracterização empírica e análise dos dados}

No primeiro momento vamos apresentar alguns dados no formato de entrevistas (obtidos por meio da aplicação de questionários) que foram fragmentadas no formato de respostas qualitativas a fim de que pudéssemos compreender melhor qual o perfil dos alunos que estudavam na Universidade Politécnica de Sáo Paulo e tentarmos confirmar a nossa primeira proposição $^{8}$ de que existe uma aproximação desses alunos com os marcadores da cultura legítima, o que por sua vez, os destina homologamente às posiçóes privilegiadas no mercado de trabalho depois de formados. Cabe mencionarmos que escolhemos nomes fictícios para nossos entrevistados a fim de levar em conta o anonimato das identidades desses egressos.

Antes de adentrarmos a averiguação heurística precendente faz-se necessário destacar como se deu o processo de geração de dados empíricos, ou seja, o caminho metodológico que antecede a exposição e análise das entrevistas. Disponibilizamos um questionário fechado no site da Associação de Engenheiros Polítécnicos (AEP), da Poli, uma associação formada por alunos egressos do curso, e fizemos chamadas contínuas para que os ex-alunos respondessem os questionários. Dentro das chamadas obtivemos 15 respondentes. Dentre as 15 entrevistas obtidas, buscamos elencar dois novos padróes de classificação: 1 - devido ao não retorno dos egressos elegíveis, fizemos uma comparação entre as 15 entrevistas fechadas obtidas pelos egressos no site e observados que havia um padráo de gostos e classes sociais que se repetia. Já que, encontrando justamente os "tipos ideais", ou modelos de capital cultural e econômico que se repetiam, não achamos necessário explorar de forma exaustiva outras entrevistas qualitativas, sendo assim, trabalhamos somente com o universo de 7 entrevistas sistematizadas; 2 - buscamos escolher pelo menos um respondente que representasse cada década $(1970,1980,1990,2000)$ e entramos em contato para que respondessem um roteiro de entrevistas com questóes abertas a fim de complementarmos as análises dos questionários fechados.

As questóes do roteiro de entrevistas tinham como objetivo tanto perfilar os indivíduos entrevistados bem como conhecer o universo da sala de

8 Testamos com esta proposição uma outra que se opõe e ela, ou seja, a de que os não detentores da cultura legítima possivelmente não ocupariam cargos de destaque no universo das finanças. No entanto partimos da observação dóxica de que os alunos da Poli-USP são alunos elitizados para depois nos afastarmos dessa prénoção evidenciando os casos de exceção que se nos aparecem. 
aula, a conduta e o comportamento dos seus colegas dentro e fora de sala de aula no período em que estudaram na universidade.

Em suma, partimos de um universo de amostragem não probabilística e intencional. Usamos como fontes para nossa sistematização tanto o questionário fechado disposto no site de egressos, quanto um roteiro de entrevistas semiestruturadas que nos auxiliou a formatar a pesquisa de forma explicativa, tendo como pressuposto, aprofundar o conhecimento de uma dada realidade e exercer a triangulaçáo metodológica na etapa de coleta quantitativa que fora realizada na mesma pesquisa.

As entrevistas fechadas e o roteiro de entrevistas aberto foram realizados de 2014 a 2015, sendo que, parte delas foi obtidas no site da AEP e outra parte via Skype. As entrevistas e conversas por Skype duraram entre trinta minutos e uma hora e, foram realizadas individualmente, seguindo as questóes do roteiro de entrevista que foi elaborado a partir de dúvidas e apontamentos encontramos nas repostas dos questionários fechados.

Depois da exposição da caracterização metodológica sobre os dados empíricos e da explanação de indicadores que puderam nortear as entrevistas, podemos averiguar o quadro prosopográfico ${ }^{9}$ de nossos entrevistados.

O primeiro deles, Sebastião, é o inquerido mais velho, entrou na década de 1960 na Poli e possui uma origem social mais alta, já que seus pais e avós cursaram o ensino universitário e sáo profissionais liberais. Ele sempre estudou em escolas particulares, frequentou um dos colégios mais renomados de São Paulo e adquiriu, portanto, condiçóes simbólicas para ser aprovado no vestibular da Poli que, no período, era um dos mais concorridos. Possui um capital cultural bastante significativo, pois frequenta teatros, exposiçóes e museus, ao mesmo tempo, faz caminhadas ao ar livre, cita a preferência por pintores de diferentes estilos e tem como gosto mais

9 De acordo com o estudioso Christophe Charle (2006), a análise prosopográfica advém dos estudos historiográficos, foi inventada desde os estudos de história antiga e medieval e está sendo desenvolvida contemporaneamente de forma muito intensa, principalmente nos últimos 40 anos. Esse método consiste em definir uma população a partir de um questionário biográfico que descreverá as dinâmicas sociais, privadas, públicas e até mesmo ideológicas ou políticas de uma população. De acordo com o autor, o primeiro e o mais longo passo da análise seria o da coleta de dados e das entrevistas através de questionários individuais. Depois desse periodo, segue-se a análise dos dados por meio de técnicas múltiplas, quantitativas, qualitativas ou de quadros estatísticos, de análises fatoriais (dependendo sempre dos dados obtidos por meio dos questionários) e documentos, de forma que a análise passa a ser feita de acordo com generalizações coletivas, pois se trata de analisar as biografias coletivamente. 
sofisticado as músicas clássicas e a MPB. No que diz respeito a sua profissão, ele é um exemplo das primeiras ocupaçóes dentro das engenharias entre os anos 1960-19670, a saber, a análise de sistemas. Depois, trabalhou como consultor da mesma empresa e recebe uma faixa salarial bastante alta em relação à média de salários no País.

O segundo entrevistado, Simão, é um exemplo muito importante de como a origem social, os capitais familiares e, posteriormente, o capital pessoal adquirido irá direcionar suas apreciaçóes e preferências para sua ocupação futura de forma muito distinta da de Sebastiáo nos anos 1960. Podemos perceber que o segundo engenheiro de produção entrevistado tem uma baixa origem social, esse fato pode ser constatado, pois seus pais estudaram até o ensino fundamental, sua mãe é dona de casa e seus pais se situam em uma faixa de renda inferior. Esse fato influencia nitidamente as adequaçóes de gosto do engenheiro, que por sua vez estudou a vida toda em colégios públicos, não viaja, não lê revistas culturais, no entanto, lê revistas de variedades sobre política e economia, não cita as músicas direcionadas à cultura legítima e menciona somente o nome de um pintor.

Finalmente, constatamos que um dos fatos mais relevantes que devem ser assinalados é o desse entrevistado ter tentado trabalhar na área financeira, mas, por algum motivo processual em sua trajetória ou pela possível ausência de algum tipo de capital cultural ou social, como assinala Grun (1992), ele não permaneceu na área mais rentável das engenharias, já que consegue trabalho justamente na área mais próxima ao "chão de fábrica”, cujos salários são mais baixos, com remuneraçóes próximas de $\mathrm{R} \$ 10.000,00$.

Temos, portanto, dois casos emblemáticos que podem nos auxiliar nas verificaçôes de nossa proposiçáo principal. Ou seja, percebemos que é justamente a adequação com relaçáo à distância ou à proximidade dos marcadores de legitimidade que direcionam as apreciações quanto ao futuro profissional dos agentes estudados. E o mais importante, no último fragmento de prosopográfico, o engenheiro inquerido evidenciou o sonho de trabalhar na área de engenharia econômica (finanças e bancos) e por fim, não conseguiu concretizar a sua preferência real.

Outro exemplo muito contundente com a proposição deste trabalho são os fragmentos da história de vida de Edgar, um aluno que estudou na Poli na década de 1970-1980 (concluinte em 1982) e que consideramos ter um estilo de vida mediano. Edgar possui uma origem social mais alta, 
seus pais detêm capital escolar, pois se formaram como universitários e atualmente trabalham como funcionários públicos. Seu pai recebe salário superior a $\mathrm{R} \$ 10.000,00$ e seu avô paterno ${ }^{10}$ era dono de fazenda e comerciante. Vê-se, portanto, na sequência geracional, a passagem do capital econômico familiar de uma geração a outra, sendo que Edgar, hoje, recebe salário superior a $\mathrm{R} \$ 20.000,00$.

Quanto ao seu capital cultural, ele se evidencia como intermediário, uma vez que essa questão não é somente constatada na entrevista, mas também pelo fato de seu legado familiar, ou seja, Edgar náo advém de uma família de profissionais liberais e sim de pequenos proprietários e funcionários públicos. $\mathrm{O}$ entrevistado assinala que visita clubes, casas de amigos, centros culturais, exposiçóes e museus, além de viajar frequentemente ao exterior, ainda no que diz respeito ao capital cultural, pratica esportes medianos como bicicleta e corrida, gosta de músicas brasileiras e lê autobiografias. Quanto a sua representatividade, usa roupas sóbrias típicas das classes altas, mas também faz a mistura típica da classe média ao usar roupas rebuscadas, explorando o "tom" do novo-rico, mas ao mesmo tempo, retoma seu ethos de classe superior escolhendo os móveis rústicos para sua residência ${ }^{11}$.

Por fim, Edgar afirma que sempre desejou trabalhar na área de engenharia econômica (bancos e finanças). Logo no começo da carreira, se inseriu em outra área, em um setor voltado para indústria, mas, em alguns anos, conseguiu reconverter sua preferência, conquistando o espaço que tanto queria no mercado de trabalho, pois assume uma funçáo profissional na área de finanças, setor no qual ainda permanece como conselheiro financeiro.

Frederico é outro entrevistado que estudou na Poli na década de 1970 e que consideramos ter um estilo de vida reconvertido, pois nasceu em uma família de classe média baixa no interior de São Paulo, cuja origem social foi marcada pelos estudos de seus pais como concluintes do ensino médio e como trabalhadores do setor público. Seu avô também cursou o ensino médio e trabalhou na comercializaçáo de medicamentos. Seus pais

10 Inquerimos os entrevistados sobre a atuação de seus avôs paternos (assim como o faz Pierre Bourdieu em sua estratégia metodológica), todavia nem todos os entrevistados mencionaram a ocupação e escolaridade de seus avós por motivos diversos,como, não se lembrar de dados referentes a esses entes.

II Gostaríamos de deixar claro que as nossas concepções sobre estilos de vida e gosto são definidas por nossas leituras das obras de Pierre Bourdieu e nos debruçamos principalmente na obra La Distintion (2008) para fazermos nossas afirmações, ao mesmo tempo, sempre levamos em conta as especificidades dos marcadores culturais e econômicos brasileiros que jamais deixamos de lado em nossas análises. 
mantêm uma renda média e expressam seu capital econômico por meio da aquisição de uma casa própria e automóvel.

Um fato relevante para a análise que deve ser mencionado é que o engenheiro conseguiu ascender socialmente, pois atualmente recebe mais que $\mathrm{R} \$ 20.000,00$ e se classifica como pertencente à classe média alta ou classe alta. Possui elevado capital econômico expresso em viagens frequentes para o exterior e apresenta expressivo capital cultural, pois cita peças de teatro, compositores clássicos e óperas. Lê livros de leitura cotidiana e consegue mencionar um número grande de autores, também faz alusão a pintores de estilos distintos, fato que marca o seu provável ecletismo de classe média. Têm como preferência as músicas mais próximas do gosto da cultura legítima como jazz, blues, choro e música clássica. Certamente, em vista de seu elevado capital cultural, que pode ter adquirido em seu processo de socialização secundária, efetiva-se em um alto cargo nas finanças sendo que começou a trabalhar no ramo dos bancos financeiros e, hoje, é presidente e acionista de um grande grupo de multinacionais.

Mauro outro egresso que estudou na Poli no final dos anos 1970 e que parece ter um estilo de vida reconvertido, é mais um entrevistado que apesar de ter pais que cursaram o ensino médio e fundamental, trabalham no ramo privado, têm um alto capital econômico, seu avô paterno era profissional liberal e cursou o ensino universitário. Tais constataçóes proporcionaram a Mauro a oportunidade de estudar em colégios privados e de adquirir certo capital cultural médio, pois declara que não vai ao teatro, não pratica esportes, prefere as leituras cotidianas e móveis modernos medianos. Possivelmente, seu capital cultural médio e um possível capital social o impulsionaram a trabalhar na área de consultorias, o que o conduziu à presidência de um grupo empresarial no futuro.

Andressa é outra ex-aluna que estudou na Poli na década de 1990 e parece possuir um estilo de vida mediano, sendo um exemplo de engenheira advinda das camadas médias, não sabemos ao certo seu salário (pressupomos que ele seja alto porque ela trabalha no mercado financeiro) e nem o salário de seus pais (que náo deve ser baixo, pois eles pagaram escola particular para ela durante a vida toda). Esse tipo de socialização permitiu que ela adquirisse algumas marcas simbólicas para ser aprovada no vestibular da Poli. Sobre seu capital cultural, ele parece ${ }^{12}$ ser mediano,

12 Descrevemos nossa análise de forma especulativa sempre levantando questionamentos e dúvidas para deixar claro que esse é o ponto de vista do pesquisador que classifica um emaranhado de dados. No entanto, a 
uma vez que assiste séries na televisão, cita somente um pintor, não gosta de música clássica e prefere móveis de tipo moderno. Suas roupas transitam no ecletismo do estilo sóbrio e adequado das classes altas para o estilo mais à vontade, traço típico do ecletismo das elites brasileiras citado por Pulici (2010). Seu desejo foi o de trabalhar no mercado financeiro e ela o realizou, trabalhando nessa área até os dias atuais.

Mirela formada na Poli no ano de 2000 parece ser a marca da mistura brasileira, pois se identifica como uma índia de classe média, cujos pais cursaram ensino superior completo e estudaram em colégios privados. Diz que seu avô era boiadeiro, o que demonstra o processo de ascensão familiar por parte de seus pais. Intrigantemente, ela estudou em colégios públicos e sonhou trabalhar com engenharia industrial. Hoje, possui uma renda média que náo ultrapassa $\mathrm{R} \$ 10.000,00$. Apesar disso, ela possui um capital cultural mediano, dado que toca piano, viaja para o exterior com frequência e vai ao teatro, a exposiçóes e museus com regularidade (isso pode ser confirmado em seu perfil de uma rede social conhecida).

Quanto a suas leituras, elas são classificadas como de classe média já que se restringem a livros técnicos e cotidianos. Mirela pratica esportes medianos, como a natação e corrida. Seu gosto por música é tido como moderno. Sobre a sua vestimenta, mistura o sofisticado e sóbrio com a grife (imperativo de certo capital econômico). Acerca de seu gosto por móveis, prefere os antigos (móveis ditos de um gosto superior). Por fim, Mirela trabalha na área de consultorias no período que corresponde à conclusão de sua graduação e os dias atuais.

Ao nos encontramos diante de um emaranhado de dados que pode nos dispersar de conclusóes mais contundentes, faz-se necessário, mesmo que de forma mais didática, organizar as ideias, a fim de apontar conclusóes mais acertadas. Para isso, construímos um quadro com a distribuição de capitais dos pais e dos filhos (engenheiros entrevistados), inserindo apenas três tipos de atribuiçóes aos capitais (alto, médio, baixo). Não queremos descaracterizar a complexidade do tema discutido, mas esse recurso didático e organizativo será importante para fazermos algumas afirmaçóes.

Antes de apresentarmos a divisão entre diferentes tipos de capitais e a sua distribuição quanto ao seu volume entre os entrevistados, cabe 
explicitarmos qual a formatação classificatória utilizamos para estabelecer o que seria a obtenção de capitais altos, médios e baixos. Logo, o quadro abaixo evidência a lógica cognitiva que estabelecemos, bem como, as referências teóricas que nos pautamos para estabelecer tal categorização.

\section{Quadro I - Princípios classificatórios para o volume de capitais}

\begin{tabular}{|l|l|l|l|}
\hline Capitais & Alto & Médio & Baixo \\
\hline $\begin{array}{l}\text { Capital } \\
\text { econômico }\end{array}$ & $\begin{array}{l}\text { Renda acima de } 10.000 \\
\text { reais } \\
\text { Casa de veraneio, mais } \\
\text { de dois automóveis, área } \\
\text { de lazer em casa'4 }\end{array}$ & $\begin{array}{l}\text { Renda entre } 5.000 \text { e } 10.000 \\
\text { reais } \\
\text { Dois ou mais automóveis } \mid \\
\text { área de lazer em casa }\end{array}$ & $\begin{array}{l}\text { Renda + ou - entre } \\
2.000 \text { de } 5.000 \text { reais } \\
\text { Um automóvel e sem } \\
\text { área de lazer em casa }\end{array}$ \\
\hline $\begin{array}{l}\text { Capital } \\
\text { cultural|' }\end{array}$ & $\begin{array}{l}\text { Arte, música, lazer e } \\
\text { leituras, vestimentas, } \\
\text { alimentação, mobiliário, } \\
\text { viagens e esportes da } \\
\text { cultura legítima }\end{array}$ & $\begin{array}{l}\text { Arte, música, lazer e leituras, } \\
\text { vestimentas, alimentação, } \\
\text { mobiliário, viagens e } \\
\text { esportes da cultura de classe } \\
\text { média }\end{array}$ & $\begin{array}{l}\text { Arte, música, lazer e } \\
\text { leituras, vestimentas, } \\
\text { alimentação, mobiliário, } \\
\text { viagens e esportes da } \\
\text { cultura da classe popular }\end{array}$ \\
\hline $\begin{array}{l}\text { Capital } \\
\text { escolar }{ }^{16}\end{array}$ & $\begin{array}{l}\text { Ensino superior } \\
\text { concluído pelos pais } \\
\text { Filhos que estudaram em } \\
\text { escolas privadas }\end{array}$ & $\begin{array}{l}\text { Ensino fundamental elou } \\
\text { médio concluído pelos pais } \\
\text { Filhos que estudaram parte } \\
\text { em escolas públicas e } \\
\text { privadas }\end{array}$ & $\begin{array}{l}\text { Pais que não estudaram } \\
\text { ou são analfabetos } \\
\text { Filhos que estudaram } \\
\text { em escolas públicas }\end{array}$ \\
\hline
\end{tabular}

Fonte: Elaborado pelos autores deste artigo

13 Quanto aos salários tomamos como parâmetro os dados do IBGE de 2012 com relação à composição salarial: Classes $A$ ganham mais do que 12.440 reais, enquanto a classe $B$ ganha de 6.220 a $R \$ 12.440$ e a classe $C$ de 2.488 a $R \$$ 6.220. Sendo assim arredondamos a renda dos entrevistados a partir desse parâmetro.

14 No que diz respeito à área de lazer e casa de veraneio, usamos esse parâmetro para a cultura legítima de acordo com Bourdieu (2008) uma vez que nesse aspecto a análise francesa se encaixava a lógica brasileira em nossa análise. No que diz respeito aos automóveis, usamos como referência os microdados da PNAD de 2009. uma vez que, estabelece-se o cruzamento entre as faixas salariais e a porcentagem da obtenção ou não de carros de acordo com a porcentagem de domicílios no Brasil. Esta explanação encontra-se na tese de doutorado da presente autora.

15 Quanto ao capital cultural, nos respaldamos na análise de Pierre Bourdieu (2008) para delimitar seu conteúdo referente à cultura legítima e ao distanciamento da cultura legítima e aproximação de uma cultura média ou popular. Ao mesmo tempo, usamos a tese de Pulici (2010) para reapropriar essas categorias para o caso do Brasil. Para compreender os pormenores de cada uma das categorias indicamos a leitura da tese da presente autora.

16 Também foi levado em conta o tipo de graduação realizada pelos pais como, universidades públicas, privadas, do Brasil ou do exterior e seu grau de consagração no mundo. Essa relação classificatória extensa encontra-se na tese da presente autora. 
Podemos observar que existem dois casos extremos em nosso quadro que compactuam com as asserções de nossa proposição: um dos egressos, cujos capitais familiares são altos, vive a realidade consequente de sua origem social por possuir capital econômico e cultural alto, e como atuação profissional, escolheu a área de consultorias. Outro caso extremo é o do egresso que possui todos os capitais familiares baixos e, portanto, seus capitais também são baixos, seu sonho de profissão era a área financeira, mas ele náo conseguiu realizá-lo, ficando circunscrito a uma área do setor industrial. Esses casos exemplificam muito bem o funcionamento da lógica de Bourdieu (2008) sobre a correspondência entre os marcadores de legitimidade e as escolhas e posiçóes tomadas pelos indivíduos.

Contudo, há três casos bastante distintos que nos mostram a singularidade de nosso país, cujas origens sociais nem sempre corresponderam à posição ocupada pelos indivíduos desde o Brasil-colônia, como assinala Carvalho (2003). Nesse emaranhado de situaçóes distintas, assinalamos que os elementos marcados no quadro em destaque correspondem justamente a essas exceçóes. Passemos à análise delas, portanto:

Quadro 2 - Marcadores de econômicos e culturais

\begin{tabular}{|l|c|c|c|c|c|c|}
\hline & $\begin{array}{c}\text { Data de } \\
\text { formação }\end{array}$ & $\begin{array}{c}\text { Capital. } \\
\text { Econ. } \\
\text { Pais }\end{array}$ & $\begin{array}{c}\text { Capital } \\
\text { Escolar } \\
\text { Pais }\end{array}$ & $\begin{array}{c}\text { Capital } \\
\text { econ. } \\
\text { Filho }\end{array}$ & $\begin{array}{c}\text { Capital } \\
\text { Cult. } \\
\text { Filho }\end{array}$ & $\begin{array}{c}\text { Capital } \\
\text { Escolar } \\
\text { filho }\end{array}$ \\
\hline Sebastião & 1970 & Alto & Alto & Alto & Alto & Escola privada \\
\hline Frederico & 1970 & Médio & Baixo & Alto & Alto & $\begin{array}{c}\text { Graduação } \\
\text { exterior }\end{array}$ \\
\hline Mauro & 1977 & Alto & $\begin{array}{c}\text { Baixo (mas } \\
\text { o do avô } \\
\text { era alto) }\end{array}$ & Alto & Médio & Escola privada \\
\hline Simão & 1982 & Baixo & Baixo & Baixo & Baixo & Escola pública \\
\hline Edgar & 1982 & Alto & Alto & Alto & Médio & ---------- \\
\hline Andressa & 1993 & Alto & Alto & Alto & Médio & Escola privada \\
\hline Mirela & 2004 & Médio & $\begin{array}{c}\text { Alto (pais } \\
\text { colégios } \\
\text { privados) }\end{array}$ & Médio & Médio & Escola pública \\
\hline
\end{tabular}

Fonte: Elaborado pelos autores deste arigo 
A primeira história diferenciada é a de Frederico, cujos pais apresentaram capital escolar baixo, mas têm uma remuneração de classe média. Esse, por exemplo, pode ter sido o elemento-chave para que sua trajetória implicasse em uma reconversão, já que seu capital econômico e o cultural se tornaram altos. Atualmente, Frederico ocupa a posição de presidência e acionista de um grupo empresarial depois de ter trabalhado em bancos financeiros.

A segunda história diferenciada é a de Mauro, mais uma trajetória que mostra como o capital econômico alto pode ser importante para alavancar a carreira de um indivíduo, já que seus pais têm um capital escolar baixo. Mauro possui um capital econômico alto e um capital cultural médio, trabalha na área de consultorias e conseguiu alcançar um cargo de presidência dentro de um grupo empresarial no qual ainda permanece hoje.

A última história diferenciada é a de Mirela, que advém de uma família com capital econômico médio e um capital escolar alto. Atualmente, Mirela consegue trabalhar no mercado financeiro em Nova York, apresenta capital econômico médio e capital cultural de classe média. Outro fato muito importante é o de que, com a exceção de Mirela, que diz ter estudado em colégios públicos (mas tinha os marcadores culturais fortemente presentes em casa por meio de seus pais), percebemos que a ocorrência dos alunos terem estudado em colégios particulares ou os pais terem estudado em colégios particulares, os ditos colégios de "alta qualidade" e mais próximos de um aprendizado da cultura legítima ou mesmo média, pode ter sido o elemento-chave para socializar os indivíduos dentro de um contexto onde a cultura dominante é mais presente, logo, abre-se à possibilidade de concorrer nos exames vestibulares às vagas muito disputadas, como é o caso das vagas na Poli. Dentro dessa mesma questão, Almeida (2007, p. 2) destaca que: “[...] a maior escolarização dos pais e das mães está em alguma medida associada à sua situação econômica e a fortiori à sua capacidade de arcar com o custo das altas mensalidades cobradas pelas "boas" escolas privadas [...]"

Em suma, existe uma barreira para a ocupação de cargos na área de finanças (ou consultorias financeiras). Essa ocupação é inviabilizada em 
consequência da composição de baixos capitais simbólicos. ${ }^{17}$ No entanto, um capital cultural médio ou de classe média, construído, muitas vezes, a partir de remuneraçóes razoáveis para se pagar uma boa escola particular, poderia ser fundamental para alavancar algumas posiçóes sociais de dirigentes. A falta de capital econômico mínimo impediria o possível desenvolvimento de um habitus voltado para a cultura média ou legítima. Dada essa insuficiência, poderíamos verificar uma situação de frustração no que diz respeito à relação entre o sonho profissional e a profissão real ocupada.

Portanto, o capital cultural médio (comprado pelo capital econômico) é no mínimo um marcador importante para que os engenheiros de produção ocupem cargos mais prestigiosos no mercado financeiro ou na área de consultorias. Como os alunos da Poli têm um capital econômico mais elevado, esse fato proporcionaria uma abertura maior e maiores possibilidades para que os alunos desenvolvessem melhor os seus capitais culturais. Sendo assim, apresentar capitais culturais tem valorosa importância para que engenheiros ocupem cargos que exigem esse tipo de marcador legítimo/médio.

Outro fato imprescindível é que não é somente a valor do diploma de uma universidade tradicional que absorve os melhores alunos com alta origem social e capital cultural, mas também a relação desse profissional com a definição do cargo que será ocupado por ele no futuro, ou o que Barbosa (2002) chama de "grau de codificação dos cargos". Isso seria justamente o controle que os engenheiros possuem sobre o seu trabalho ou sobre a ocupação de um cargo. Citado esse recurso, a autora menciona mais dois elementos indispensáveis para o processo de codificaçáo dos cargos.

O primeiro deles é o "grau de controle sobre o conhecimento abstrato", ou seja, "as pretensôes legitimadas" do grupo, como seu grau de cientificidade (no caso do engenheiro, a sua habilidade com o cálculo, física e matemática que lhe trazem grande legitimidade para ocupar um cargo superior). O segundo recurso é a relação que se estabelece entre o

17 A esse respeito, Collins (1979) dá o exemplo de que algumas empresas específicas, na América do Norte, exigem altos requisitos educacionais para a contratação de cargos diretivos (como é o caso das empresas públicas de trust - voltadas para áreas de serviços financeiros, médicos, legais, engenharias e contabilidades). 
profissional com o conhecimento, que pode impulsionar o desenvolvimento de outros critérios que não sejam técnico-profissionais, a saber, o capital social e o "capital cultural e familiar" podem ser tomados como exemplos.

\section{A diferenciação dos alunos da Universidade Politécnica de São Paulo quanto aos marcadores de legitimidade e seus direcionamentos profissionais}

Para além das histórias sobre o gosto e estilos de vida que mapeamos sobre os egressos da Poli, abordaremos duas entrevistas, pois esses dados podem nos abrir possibilidades para pensarmos e ilustrarmos as reais falas dos indivíduos de "carne e osso" sobre seus marcadores de legitimidade e sobre as suas apreciaçóes sobre o setor que seguiram em suas carreiras.

\section{Quadro 3 - Entrevista com egresso da Poli que atua como professor e consultor (formado em 1992)}

O ex-aluno nos reportou que a maioria dos alunos de sua sala tinha como sonho de carreira trabalhar em bancos de investimentos ou em consultorias estratégicas. Poucos escolhiam se dedicar às operações (manufatura, PCP, logística e qualidade).

No que diz respeito ao perfil socioeconômico dos seus colegas, ele afirmou que aproximadamente 15\% eram de classes altas, $80 \%$ de classes médias e $5 \%$ de classes baixas.

Relatou que os alunos de classe mais alta tinham como fator de distinção carros, casas em praia, viagens para o exterior e praticavam esportes diferenciados. Ressaltou que esses alunos estudaram somente em colégios particulares. Entretanto, a principal diferença para se localizar um aluno de classe alta em sua sala de aula estava nas viagens para o exterior.

Normalmente, as áreas de trabalho escolhidas pelos alunos de classe alta eram, essencialmente, as áreas de bancos de investimento.

No que diz respeito ao tempo livre e atividades culturais, na Poli, sobrava pouco tempo. Os alunos não ouviam muita música e os alunos escolhiam como esporte a prática da natação, tênis, ou atletismo. A forma como os alunos de classes mais baixas de sua sala eram distinguidos era justamente pela falta de veículo próprio. Esses alunos também tinham sido bolsistas de escolas particulares. Os alunos de classes mais baixas tinham como escolha trabalhar nas áreas de operação dentro das indústrias.

Fonte: Elaborado pelos autores deste artigo

Os fragmentos da entrevista realizada com um professor e atual consultor que é da turma de 1992 mostram que o sonho de carreira dos alunos já era o mercado financeiro e as consultorias estratégicas nessa turma de in- 
gressantes de 1992. O egresso assinalou que sua turma era em grande parte de classe média e que os alunos de classe mais alta escolhiam trabalhar no mercado financeiro. Citou justamente os esportes destinados a classes medias-altas de acordo com Bourdieu (2008) - natação, tênis e atletismo -, que classificamos entre os esportes médios e requintados. Ademais, apontou que os alunos de menor renda escolhiam trabalhar justamente nas indústrias.

À vista disso, devemos retomar Collins (1979) que afirma que a ideia de credencialismo nos capacita para melhor compreender a relação entre as classes e as instituiçóes escolares. Logo, apoiado em pesquisas realizadas nos Estados Unidos, ele afirma que algumas instituiçôes recompensam e socializam justamente os indivíduos de classe média, na medida em que são esses os alunos que estudam em escolas prestigiosas: são eles que tomarão o poder e assumirão grandes cargos no mercado de trabalho. Ao se valorizar traços típicos específicos de uma classe média, esses indivíduos garantem posiçóes de poder, enquanto outros indivíduos que adquirem credenciais (diplomas) em outras instituições não prestigiosas ficam alijados de algumas posiçóes de poder.

Logo, constata-se que a existência de diplomas de instituiçóes com maior peso simbólico e outras com menor peso simbólico (que comumente recebem estudantes de classes mais baixas) seria o ponto nevrálgico da questão da desigualdade escolar, que impóe aos indivíduos exatamente a posição que eles devem ocupar no mercado de trabalho e os passos a serem seguidos para construir sua carreira. 


\title{
Quadro 4 - Entrevista com egresso, microempresário e professor (formado na Poli em 2005) ${ }^{18}$
}

\begin{abstract}
Para detalhamento da questão anterior, é questionado ao entrevistado se a grade do curso da Poli possui disciplinas que direcionam os alunos ao mercado financeiro. Comentamos que a UFSCAR ${ }^{18}$ forma engenheiros que vão para as indústrias.
\end{abstract}

"O curso, na verdade, nos inibe. Os professores são contra, fazem contra apologia, preparam-nos pouco nos conteúdos específicos de finanças. Eu acho que é uma questão meramente geográfica, sinceramente. Acho que se a UFSCar fosse em São Paulo e a Poli em São Carlos, do jeitinho como são, a tendência seria ao contrário. Com os mesmos alunos, mesmos professores, mesma grade. É... mas assim... o curso não nos prepara bem para o dia a dia do mercado financeiro. O pessoal chega estagiário, vai aprendendo, pega o jeito da coisa e aí continua. Entende? Falo isso do lado de fora, porque nunca trabalhei no mercado financeiro. Mas não acho que ali estão as melhores mentes da teoria de finanças... pra mim são as pessoas que se adequaram melhor naquele estilo de vida. Ou seja, o pessoal de São Carlos também deve ser atraído por essas áreas, mas começa um pouco atrás por uma questão de experiência e não de preparo."

Pergunto se ele conhece alunos das universidades particulares em São Paulo e se eles também vão atuar no mercado financeiro por conta da questão geográfica.

"Eu conheço pouca gente que faz Produção nas particulares. E quem eu conheço está no início do curso. Mas, honestamente, eu acho que o mercado financeiro tem um preconceito grande com as particulares de engenharia. É uma visão que eu tenho, mas esse pessoal de consultoria estratégica e mercado financeiro tem uma cabecinha assim: bom é ITA, Poli, FEA, FGV, UFSCar. Posso até te mostrar um site de uma consultoria que já limitava a esses cursos das particulares. Mas no caso da engenharia na GV é ao contrário, é super bem vista. E o pessoal vai em massa pro mercado financeiro (só para ilustrar, veja a pergunta 2 desta prova de uma das maiores consultorias estratégicas do mundo, a BCG). Veja a pergunta 2... não tem Mackenzie, FEI, Mauá (que são as faculdades mais famosas de engenharia de produção particulares)."

Sobre as suas escolhas na carreira, quais motivos o fizeram escolher a área que atua:

"Minha história é um pouco complicada e incomum. Eu saí da faculdade para a Embraer, ou seja, para a indústria (apesar de ter uma paixão pela teoria de finanças e mercado de capital, o estilo de vida e o perfil das pessoas definitivamente não são para mim). Mas muito pouco tempo depois de formado eu tive enormes problemas pessoais (perdi minha mãe, tenho irmãos mais novos e um pai muito doente) e voltei para a minha cidade. Estou trabalhando hoje no negócio da família, dou aulas de engenharia de Produção na faculdade daqui de Presidente Prudente e dou consultoria industrial em algumas indústrias da região. Antes, eu escolhi a área indústria por paixão... remunerava menos que as outras propostas que eu tinha, mas eu queria muito atuar ali, tinha orgulho de estar em uma grande indústria e sempre tive muita atração por empreendedorismo. Então queria ter um contato com a produção "de verdade". Eu tive uma pontada de dúvida com consultoria estratégica, pelo aprendizado e crescimento rápido, mas eu sempre me enxerguei mais feliz trabalhando em um lugar que eu via "produtos saindo" e tudo mais.

Questionamento sobre o motivo pelo qual ele não escolheu mercado financeiro como a maior parte dos alunos de sua sala.

"Isso é uma opinião, talvez até preconceituosa, mas é minha visão que me afastou deste mercado. Eu acho que é uma área em que as pessoas pensam pouco, fazem muita coisa no impulso e ostentam muito sua rapidez e "genialidade". Não gosto disso, eu gosto de reflexão, planejamento, pensamento profundo. Além disso, as pessoas no geral são muito arrogantes e precisam muito sustentar isso. E pra terminar, é um ritmo de vida que pra mim é insano: ficar 16 horas no trabalho, sendo boa parte do chamado "face-time" (estar lá porque é importante estar lá). Eu gosto de contato com família e gosto de ser produtivo na hora que eu trabalho... por isso o empreendedorismo me atrai tanto".

Fonte: Elaborado pelos autores deste artigo

18 Citamos o caso da UFSCar que foi estudada em nossa pesquisa de doutorado, mas no caso desse artigo, optamos por analisar somente a Poli, pois o espaço deste artigo é bastante restrito o que prejudicaria a análise das duas universidades em conjunto. Obteríamos fragmentos curtos e não aprofundados sobre os dados de cada universidade o que inviabilizaria uma discussão mais apurada e significativa. 
A entrevista no Quadro 4 é uma das mais importantes sistematizaçóes que realizamos, pois traz muitas informaçóes importantes para a pesquisa. O aluno ressalta que, na década de 1990, as áreas mais desejadas eram indústria e mercado financeiro (para os que queriam mais rentabilidade financeira) e, por último, as consultorias estratégicas, um setor intermediário entre os dois anteriores. Sobre os indivíduos de classes mais altas, o respondente, hesita e titubeia com a resposta de que não existe uma definição de setor para essa classe social, mas, depois acaba assumindo o fato de que os engenheiros mais abastados acabam indo para o mercado financeiro e consultorias.

Quando o questionamos sobre a razão pela qual essa escolha se dá, ele admite a assertiva de que é devido ao fato de estarem em Sáo Paulo, onde o mercado financeiro e as grandes companhias de consultoria se situam. No entanto, quando insistimos um pouco mais na questão, o entrevistado se contradiz dizendo que ali estão "as melhores mentes das teorias das finanças" e se contraria novamente com a asserção da importância do mercado financeiro estar em São Paulo ressaltando que os alunos de outra universidade pública ficam atrás por não terem experiência. ${ }^{19}$

Esse último adjetivo, cujo significado semântico designa falta de experiência, mascara, na realidade, a ausência de "marcadores simbólicos de legitimidade", o que possivelmente também é a razão pela qual os engenheiros de produção das universidades particulares de São Paulo não conseguem entrar no mercado financeiro e na área de consultorias, mesmo residindo na cidade de São Paulo.

$\mathrm{O}$ ex-aluno entrevistado atribui à fatalidade do falecimento de sua mãe um fator determinante para que ele tomasse as escolhas que fez e seguisse o caminho dentro da indústria. Poderíamos pensar, nesse ponto, que um acontecimento, ato aleatório ou o processo pelo qual o indivíduo forja seu ato ou escolha profissional possa ter impulsionado sua escolha final.

19 Essas experiências tanto para a Poli quanto para outras universidades públicas são adquiridas no estágio, mas durante a pesquisa percebemos que alunos de outras universidades públicas não são convocados para esses estágios ao contrário dos alunos da Poli que são frequentemente selecionados. Na discussão mais aprofundada em nossa tese de doutorado constatamos que os alunos da UFSCar possuem um volume de capital simbólico menor do que o dos alunos da Poli. 
No entanto, indo um pouco mais longe, observamos que esse entrevistado se diz apaixonado pelas teorias das finanças, apesar de contraditoriamente ter ido trabalhar na indústria: não conseguiu adentrar as áreas de finanças ou não faz esse tipo de opção.

O asco e o repúdio pelo pessoal "arrogante" que "ostenta sua rapidez e genialidade" soa como mecanismo de defesa, além de repercutir também o discurso que coloca o "outro" dentro de um espaço que não lhe serve como sua luta pessoal. Por isso, percebemos, aqui, que para além de um acontecimento em sua vida que tenha forjado sua escolha final, existem algumas disposiçóes no indivíduo, marcadas pela aversão à postura do financista, que pode ter sido um dos elementos incisivos que contribuíram para sua escolha. Ou seja, apesar do estímulo do falecimento (acontecimento cotidiano), havia uma estrutura simbólica que expunha o seu gosto e o seu desgosto pelas ocupaçóes entre as quais ele deveria escolher para o futuro. A “reflexão, o planejamento e pensamento profundo ${ }^{20}$ " passam a adquirir caráter distintivo, que o diferem do mercenário (homem das finanças), que paradoxalmente não deixa de ser genial e de ser a melhor das "mentes" recrutadas. O seguinte excerto do estudo de Bourdieu (2008, p. 225) confirma nossas asserçôes ao discutir as afinidades eletivas:

O senso social encontra suas referências no sistema de sinais indefinidamente redundantes entre si de que cada corpo é portador - vestuário, pronúncia, postura, forma de andar, maneiras - e que, registrados inconscientemente, encontram-se na origem das "antipatias" ou "simpatias": as "afinidades eletivas", aparentemente, mais imediatas baseiam-se sempre, por um lado, na decifração inconsciente de traços expressivos em que cada um só adquire sentido e valor no interior do sistema de suas variações segundo as classes (basta pensar nas formas do riso ou do sorriso repertoriadas pela linguagem comum). O gosto é o que emparelha e assemelha coisas e pessoas que se ligam bem e entre as quais existe um mútuo acordo.

\section{Conclusão}

Em suma podemos considerar que os gostos e os capitais simbólicos dos egressos de engenharia de produção da Poli obtiveram influência no

20 Que na verdade não são as definições atribuidas a um gerente industrial, pois a essa ocupação é atribuida a condição de possuir somente habilidades técnicas. (dados concretizados na fala de um professor de engenharia de produção da UFSCar). 
capital de chegada desses indivíduos, a saber, são homólogos às posições ocupadas por esses indivíduos em cargos financeiros bem como em cargos industriais. As ocupaçóes voltadas para os cargos de finanças exigem altos marcadores culturais (sejam esses comprados ou não por um capital econômico mínimo) e os cargos industriais são majoritariamente ocupados por politécnicos que não possuíam uma origem social mais alta e não conseguiram construir uma trajetória que se aproximasse da cultura legítima. $\mathrm{Ou}$ seja, podemos dizer que compartilhamos no Brasil da magia da reproduçáo social, das afinidades eletivas e do desenvolvimento do gosto e do desgosto por estilos de vida que traçam e direcionam a trajetória dos indivíduos que trabalham no mundo das finanças.

Dentre os fatos relevantes que merecem menção estão às características indicadas em conversas com um dos professores da instituição, a saber, o "falar bem e ter poder de negociação". A primeira delas estaria inscrita dentro da esfera do capital cultural que se aproxima a cultura legítima, a segunda delas estaria relacionada a uma dada desenvoltura social para lidar com situaçóes complexas, característica associada a alguns conhecimentos de vida relativos à cultura e também ao um habitus reflexivo, criativo, intuitivo e carismático, ou seja, características opostas às do indivíduo que possui um conhecimento técnico. Recorremos a Almeida (2007) e seu estudo sobre o modo de se avaliar os alunos em exames vestibulares, quando se atribui competência aqueles que têm potencial "criativo" e não o dito "executor", ou técnico, uma vez que, os adjetivos "criativo" e "reflexivo" fariam jus à cultura legítima.

Fazemos um paralelo, portanto, apontando as habilidades simbólicas anteriores citadas pela autora e inscritas nessa disposição dos indivíduos que realizam o exame vestibular e obtêm as melhores notas, é exatamente o mesmo tipo de exigência que se propóe no momento em que os engenheiros de produção assumem um cargo no mercado financeiro ou na área de consultorias.

No entanto, constatamos a não homogeneidade dessa fração de elite estudada já que, dentro dela conseguimos visualizar várias clivagens distintas, em um espaço social de lutas, pelo reconhecimento, por melhor prestígio e melhores salários. Essa luta é contida de marcadores simbólicos 
que ora se distanciam e ora se aproximam da cultura legítima. Esse último fato, ocorre dentro de uma esfera "micro", ou seja, dentro de uma mesma universidade, com relação aos alunos que fizeram o mesmo curso de engenharia de produção.

Em suma, para além de descrever e analisar as falas prosopográficas referentes aos capitais, gostos e estilos de vida do grupo social estudado, o nosso objetivo ao realizar esse estudo foi não só o de examinar como a dinâmica dos conceitos de reprodução social e de reconversão social dessa elite para o mundo das finanças, mas como ela acaba por fortalecer e fundamentar cada vez mais os baldrames do capitalismo financeiro. Por isso, para além das organizaçôes dos capitais simbólicos e do mecanismo de reprodução assinalados pelo artigo, cabe apontar que esse novo grupo que gesta e geri as finanças passa a ditar as regras mediante um capitalismo propriamente financeiro. Portanto, cabe aos pesquisadores e cientistas sociais atentar-se para esse novo agente e para as novas agências que roboram cada vez mais os jogos de dominaçáo no Brasil.

\section{Referências}

ALMEIDA, A. M. F. A noção de capital cultural é útil para se pensar o Brasil? In: ZAGO, N. et al. (Org.). Sociologia da educação: pesquisa e realidade. Petrópolis: Vozes, 2007.

BARBOSA, M. G.; MARQUES, S. Arquitetos e Engenheiros: a arte e a ciência nos conflitos profissionais. 2002. Disponível em: <http://portal.anpocs.org/portal/index.php?option=com_ docman\&task=doc_download\&gid=4469\&Itemid=317>. Acesso em: 22 set. 2015.

BOURDIEU, P. La distinction: critique sociale du jujement. Paris: Minuit, 2008.

Os três estados do capital cultural. In: NOGUEIRA, Maria Alice; CATANI, Afranio.

(Org.). Escritos sobre educação. Petrópolis: Vozes, 2007.

CARVALHO, J. M. A construçáo da ordem: a elite política imperial. Rio de Janeiro: Civilização Brasileira, 2003.

CHRISTOPHE, C. Les Élites de la République (1880-1900). Annales, Économie, Societé, Civilisation, Paris, v. 43, n. 5, p. 1161-1165, 1988.

COLLINS, R. The credential society: an historical sociology of education and stratification. New York: Academic Press, 1979.

D’Alessandro, A. A Escola Politécnica de Sáo Paulo: histórias de sua história. São Paulo: Revista dos Tribunais, 1943. 
GRUN, R. Japão, Japões: algumas consideraçôes sobre os papéis dos conflitos intergerenciais na difusão das novidades organizacionais. In: SOARES, Rosa Maria Sales de M. (Org.). Gestáo da qualidade: tecnologia e organização. Brasília (DF): Cadernos Codapan, 1992.

HUBER, G.; SOUZA, F. B. Escola Politécnica: 100 Anos. São Paulo: Expressão e Cultura, 1993.

PULICI, C. O charme (in) discreto do gosto burguês paulista: estudo sociológico da distinção em São Paulo. São Paulo. Tese (Doutorado em Sociologia) - Faculdade de Filosofia, Letras e Ciências Humanas. USP, 2010.

\section{University consecration, symbolic capitals and financial positions: The study of the profile of production engineers at the Polytechnic University of São Paulo}

\section{Abstract}

The main objective of this article is to highlight the analysis of symbolic capital, tastes and lifestyles of production engineers (students and ex students) of the Polytechnic University of São Paulo (USP). We will enjoy this article through the qualitative methodology and consequent use of semi-structured interviews, the proposition that the symbolic markers aforementioned direct these engineers (managers) for positions in the finance world, as such, financial consulting and financial market. In short terms, we can see that, there are homologies with respect to the mentioned symbolic markers and the occupation of these engineers in recent prominent positions. Beyond the previous observation, it should be mentioned that these heralds of finance are just the new agents that are mediating and feeding dynamics and power plays within the current financial capitalism.

Keywords: Symbolic capital. Taste. Life styles. Pierre's Bourdieu Sociology. Finance and economic Sociology. 